\title{
Cost minimization analysis of laparoscopic surgery for colorectal cancer within the enhanced recovery after surgery (ERAS) protocol: a single-centre, case-matched study
}

\author{
Michał Pędziwiatr ${ }^{1}$, Mateusz Wierdak ${ }^{1}$, Michał Nowakowski $^{2}$, Magdalena Pisarska $^{1}$, Maciej Stanek ${ }^{1}$, \\ Michał Kisielewski ${ }^{1}$, Maciej Matłok ${ }^{1}$, Piotr Major ${ }^{1}$, Stanisław Kłę ${ }^{3}$, Andrzej Budzyński ${ }^{1}$ \\ ${ }^{1} 2^{\text {nd }}$ Department of General Surgery, Jagiellonian University Medical College, Krakow, Poland \\ ${ }^{2}$ Department of Medical Education, Jagiellonian University Medical College, Krakow, Poland \\ ${ }^{3}$ Stanley Dudrick Memorial Hospital, Skawina, Poland
}

Videosurgery Miniinv 2016; 11 (1): 14-21 DOI: $10.5114 /$ wiitm.2016.58617

\begin{abstract}
Introduction: The goal of modern medical treatment is to provide high quality medical care in a cost-effective environment.

Aim: To assess the cost-effectiveness of laparoscopic colorectal surgery combined with the enhanced recovery after surgery protocol (ERP) in Poland.

Material and methods: We designed a single-centre, case-matched study. Economic and clinical data were collected in 3 groups of patients (33 patients in each group): group 1 - patients undergoing laparoscopy with ERP; group 2 laparoscopy without ERP; group 3 -open resection without ERP. An independent administrative officer, not involved in the treatment process, matched patients for age, sex and type of resection. Primary outcome was cost analysis. It was carried out incorporating institutional costs: hospital bed stay, anaesthesia, surgical procedure and equipment, drugs and complications. Secondary outcomes were length of stay (LOS), readmission and complication rate.

Results: Cost of laparoscopic procedure alone was significantly more expensive than open resection. However, implementation of the ERAS protocol reduced additional costs. Total cost per patient in group 1 was significantly lower than in groups 2 and 3 (EUR 1826 vs. EUR 2355.3 vs. EUR 2459.5, $p<0.0001$ ). Median LOS was 3, 6 and 9 days in groups 1, 2 and 3 respectively ( $p<0.001$ ). Postoperative complications were noted in $5(15.2 \%), 6(18.2 \%)$ and 13 (39.4\%) patients in groups 1, 2, 3 respectively $(p=0.0435)$.

Conclusions: In a low medical care expenditure country, minimally invasive surgery combined with ERP can be a safe and a cost-effective alternative to open surgery with traditional perioperative care.
\end{abstract}

Key words: enhanced recovery, colorectal cancer, laparoscopy, perioperative management, postoperative complications, fast-track.

\section{Introduction}

The goal of modern medical treatment is to provide high quality medical care in a cost-effective environment. Nowadays an extremely important factor in clinical decision-making is health economics. This aspect is often as relevant as evidence-based medical practice, especially to national medical care providers. Therefore thorough cost-effectiveness evaluations of practically all new technologies and protocols 
are routinely performed. In the field of surgery it usually means not only the surgical procedure itself but also hospital stay, potential complication costs, as well as postoperative recovery after discharge. Although there is enough evidence to support the benefits of laparoscopic surgery in both short- and longterm outcomes, its implementation in developing countries remains challenging, mostly due to higher operative costs and lack of expertise [1-5].

Over the last decade substantial changes have also been made in perioperative care. Due to enhanced recovery after surgery programmes (ERPs), where the main goal is to attenuate postoperative metabolic stress, it is possible to reduce complication rates and shorten length of stay, which is crucial in every oncological patient. Several studies have confirmed that modern evidence-based multidisciplinary perioperative care is safe and feasible in most hospitals [6-10]. Despite the strong evidence and clear guidelines on perioperative care in colorectal surgery according to Enhanced Recovery After Surgery Society principles, their adoption among medical staff is slow [11-13]. The reason for this phenomenon is the reluctance to accept modern perioperative care strategies that differ from personally preferred practice, and the misconception of an increased complication rate, which in turn might generate additional costs [14].

According to Kehlet, often referred to as the father of fast-track surgery, economic benefits of laparoscopy and ERP would doubtlessly promote their wider adoption [15]. Although recent analyses support the cost-effectiveness of ERP, they cover only high-income countries and include mixed open and laparoscopic groups [16-20]. Since no study has investigated this topic in a country with limited expenditure on health care, we aimed to assess the cost-effectiveness of laparoscopic colorectal surgery combined with ERP in Poland.

\section{Material and methods}

We designed a case-matched study to analyse direct treatment costs of patients undergoing colorectal resection for cancer. Inclusion criteria were: age $\geq 18$ years, elective surgery, suitable for curative resection involving only the large intestine, laparoscopic or open technique (depending on the study group), ASA 1-3. Patients with inflammatory bowel diseases, after previous colorectal resection, stage
IV cancers or patients with incomplete medical data were excluded from the analysis.

Between May and August 2014, economic and clinical data were prospectively collected on consecutive patients undergoing laparoscopic colorectal resection within ERP. They formed study group 1. Using ICD-10 diagnostic codes and ICD-9 procedure codes patients were matched by an independent administrative officer for age, sex and type of resection with two historical control groups. To avoid potential bias the officer was not aware of the study concept. Group 2 consisted of patients undergoing laparoscopic resection with traditional perioperative care (between January and May 2012) and group 3 comprised patients undergoing open resection with traditional care between January and April 2010. Each group consisted of 33 patients (Table I). There were no differences between groups in terms of sex, age, body mass index (BMI), ASA grade and type of surgery. A comparison of the two perioperative protocols (traditional vs. ERP) is presented in Table II.

We are a tertiary referral centre and university teaching hospital. All operations were performed by the same laparoscopic surgeon (AB) with extensive expertise in colorectal surgery (more than 250 open and 200 laparoscopic colorectal resections). Clinical and economic data were recorded in an electronic database up to 30 days after surgery. The primary outcome was cost analysis from the institutional perspective. It was carried out incorporating costs of hospital bed stay, anaesthesia, surgical procedure and equipment, drugs, complications and readmissions and potential reoperations. It was performed by the use of an integrated hospital cost management programme. We used a micro-costing technique in which the frequencies of each resource consumed were recorded and multiplied by their unit cost. All costs were presented per case and were converted to euro from original currency (1 euro $=4.17$ Polish zloty, PLN). As patients were treated in different time frames, to avoid the potential bias in differences of medical costs between groups, they were adjusted for inflation and calculated according to the hospital price list at the time of study group 1 . Secondary outcomes were length of stay, readmission and complication rate graded with the Clavien-Dindo scale [21].

The study obtained ethical approval from the local Ethics Review Committee (Approval number: 
Table I. Demographic characteristics and types of surgery

\begin{tabular}{|c|c|c|c|c|}
\hline Parameter & $\begin{array}{c}\text { Group } 1 \\
\text { (Laparoscopic + } \\
\text { ERP) }\end{array}$ & $\begin{array}{c}\text { Group } 2 \\
\text { (Laparoscopic + } \\
\text { traditional) }\end{array}$ & $\begin{array}{c}\text { Group } 3 \\
\text { (Open }+ \\
\text { traditional) }\end{array}$ & $P$-value \\
\hline Number of patients, $n$ & 33 & 33 & 33 & - \\
\hline Females, $n(\%)$ & $18(54.5)$ & $16(48.5)$ & $20(60.6)$ & 0.6132 \\
\hline Males, $n(\%)$ & $15(45.5)$ & $17(51.5)$ & $13(39.4)$ & \\
\hline Age, mean \pm SD [years] & $66.2 \pm 11.7$ & $64.0 \pm 11.4$ & $65.8 \pm 10.9$ & 0.9385 \\
\hline Body mass index, mean $\pm \mathrm{SD}\left[\mathrm{kg} / \mathrm{m}^{2}\right]$ & $26.8 \pm 6.3$ & $26.2 \pm 3.9$ & $26.3 \pm 6.1$ & 0.9465 \\
\hline ASA $1, n(\%)$ & $2(6)$ & $5(15)$ & $4(12)$ & 0.7289 \\
\hline ASA $2, n(\%)$ & $21(64)$ & $19(58)$ & $22(67)$ & \\
\hline ASA $3, n(\%)$ & $10(30)$ & $9(27)$ & $7(21)$ & \\
\hline General anaesthesia time, mean \pm SD [min] & $210.2 \pm 45.1$ & $204.2 \pm 55.9$ & $155.7 \pm 70.1$ & 0.0011 \\
\hline Right hemicolectomy, $n$ (\%) & $15(45.5)$ & $15(45.5)$ & $16(48.5)$ & 0.9982 \\
\hline Left hemicolectomy, $n(\%)$ & $4(12.1)$ & $3(9.1)$ & $3(9.1)$ & \\
\hline Sigmoid resection, $n(\%)$ & $4(12.1)$ & $5(15.2)$ & $4(12.1)$ & \\
\hline Rectal resection + TME, $n(\%)$ & $10(30.3)$ & $10(30.3)$ & $10(30.3)$ & \\
\hline
\end{tabular}

$\mathrm{KBET} / 53 / \mathrm{B} / 2014)$ and was performed in accordance with the ethical standards laid down in the 1964 Declaration of Helsinki and its later amendments. Informed consent was obtained from all patients before surgery.

\section{Statistical analysis}

To detect a relevant difference of $15 \%$ in overall treatment costs with a two-sided significance level of 0.05 and a power of $80 \%$, it was calculated that 33 patients per study arm would be required. Statistical analysis was performed using StatSoft Statistica v.10. Groups were compared using the $\chi^{2}$ Pearson test for categorical variables. The Kruskal-Wallis test was used to assess non-normally distributed continuous data. Results were considered statistically significant when $p$-value was $<0.05$.

\section{Results}

We observed that the general anaesthesia time was significantly shorter in group 3 (open surgery). Table III presents mean direct costs of treatment in analysed groups. Laparoscopic operations were significantly more expensive than open surgery. Due to shortening length of stay (LOS), costs of bed stay and drugs were lowest in group 1. Total cost per patient in group 1 was significantly lower than in groups 2 and 3 (EUR 1826 vs. EUR 2355.3 vs. EUR 2459.5, $p<0.0001$ ).

Secondary outcomes are presented in Table IV. Median LOS was 3 days in group 1, 6 days in group 2 and 9 days in group 3 ( $p<0001)$. Postoperative complications were noted in 5 (15.2\%), 6 (18.2\%) and 13 (39.4\%) patients in groups $1,2,3$ respectively $(p=$ 0.0435).

In total, 3 patients required an intensive care unit (ICU) stay - 1 patient from group 1 (1 day) and 2 patients in group 3 ( 6 and 2 days, both due to cardiopulmonary failure) ( $p=0.3564)$.

Reoperation was necessary in 1 patient (group 1) readmitted due to anastomotic leakage. This patient was our only mortality in all of the study groups. She died after 1 day in the ICU as a result of myocardial infarction during relaparotomy for anastomotic leakage 7 days after the primary surgery.

Readmission within 30 postoperative days was necessary in 2 patients from group 1 and 1 patient from group 2 . There were no readmissions in group $3(p=0.3564)$. The reasons for readmissions were bleeding from the anastomotic suture line (2 patients) and anastomotic leakage on the $7^{\text {th }}$ postoperative day (1 patient mentioned above). 
Table II. Enhanced recovery after surgery protocol compared with standard care protocol

\begin{tabular}{|c|c|c|}
\hline Variable & Standard care & Enhanced Recovery After Surgery Protocol \\
\hline Before admission & $\begin{array}{l}\text { Surgical and anaesthesia consultation } \\
\text { Perioperative risk assessment } \\
\text { Admission } 1 \text { day before surgery }\end{array}$ & $\begin{array}{l}\text { Surgical and anaesthesia consultation } \\
\text { Perioperative risk assessment } \\
\text { Patient education including ERAS principles, } \\
\text { treatment goals, discharge criteria and expected } \\
\text { length of stay } \\
\text { Smoking cessation } \\
\text { Prehabilitation ( } 30 \text { min walks } 2 \text { weeks prior to } \\
\text { surgery) } \\
\text { Admission } 1 \text { day before surgery }\end{array}$ \\
\hline Before surgery & $\begin{array}{l}\text { Mechanical oral bowel preparation (Fortrans or Citra- } \\
\text { fleet) } \\
\text { Clear fluids up to } 8 \mathrm{~h} \text { before surgery } \\
\text { Antibiotic prophylaxis (preoperative cefuroxime } 1.5 \mathrm{~g} \\
+ \text { metronidazole } 0.5 \mathrm{~g} \text { i.v. } 30-60 \text { min prior to surgery) }\end{array}$ & $\begin{array}{l}\text { No bowel preparation (excluding rectal resection } \\
\text { with total mesorectal excision (TME) } \\
\text { Solid meals up to } 6 \mathrm{~h} \text { and clear fluids up to } 2 \mathrm{~h} \\
\text { before surgery } \\
\text { Preoperative carbohydrate loading ( } 400 \mathrm{ml} \text { of } \mathrm{Nu} \text { - } \\
\text { tricia preop. } 2 \mathrm{~h} \text { before surgery) } \\
\text { Antibiotic prophylaxis (preoperative cefuroxime } \\
1.5 \mathrm{~g}+\text { metronidazole } 0.5 \mathrm{~g} \text { i.v. } 30-60 \text { min prior } \\
\text { to surgery) } \\
\text { Deep vein thrombosis (DVT) prophylaxis (clexane } \\
40 \mathrm{mg} \text { s.c. starting in the evening prior to surgery) }\end{array}$ \\
\hline Perioperatively & $\begin{array}{l}\text { Open surgery (longitudinal incision) or laparoscopic } \\
\text { approach (longitudinal minilaparotomy for specimen } \\
\text { extraction) } \\
\text { Non-balancedintravenousfluidtherapy }(2500-4500 \mathrm{ml} \\
\text { intravenous crystalloids during the day of surgery - } \\
\text { amount decided by anaesthetist and surgeon) } \\
\text { Peritoneal drainage after each type of surgery } \\
\text { Avoidance of prophylactic nasogastric tubes } \\
\text { Anti-emetics according to instructions given by an- } \\
\text { aesthetist }\end{array}$ & $\begin{array}{l}\text { Laparoscopic surgery (transverse minilaparotomy } \\
\text { for specimen extraction) } \\
\text { Balanced intravenous fluid therapy ( } 2500 \mathrm{ml} \\
\text { intravenous fluids during the day of surgery, so- } \\
\text { dium restriction) } \\
\text { Avoidance of prophylactic nasogastric tubes and } \\
\text { drains } \\
\text { Postoperative nausea and vomiting prophylaxis } \\
\text { ( } 8 \text { mg dexamethasone i.v., ondansetron } 8 \mathrm{mg} \text { i.v.) }\end{array}$ \\
\hline Postoperatively & $\begin{array}{l}\text { Analgesia decided by anaesthetist and surgeon } \\
\text { Introduction of clear fluids on } 2^{\text {nd }} \text { postoperative day } \\
\text { Introduction of oral diet on } 3^{\text {rd }} \text { postoperative day } \\
\text { DVT prophylaxis (Clexane } 40 \mathrm{mg} \text { s.c. starting on the } \\
1^{\text {st }} \text { postoperative day) } \\
\text { Mobilization on the } 2^{\text {nd }} \text { day after surgery } \\
\text { Removal of urinary catheter when patient fully mo- } \\
\text { bilized }\end{array}$ & $\begin{array}{l}\text { Non-opioid multimodal analgesia } \\
\text { Transversus abdominis plane block } \\
\text { Introduction of clear fluids } 2 \mathrm{~h} \text { after return to } \\
\text { ward } \\
\text { Oral nutritional supplement in the evening on the } \\
\text { day of surgery (Nutricia Nutridrink) } \\
\text { Postoperative oxygenation therapy } \\
\text { Introduction of oral diet on } 1^{\text {st }} \text { postoperative day } \\
\text { Early mobilization } 2 \mathrm{~h} \text { after return to ward } \\
\text { Early removal of urinary catheters ( }<24 \mathrm{~h} \text { post- } \\
\text { operatively) }\end{array}$ \\
\hline Discharge & $\begin{array}{l}\text { Discharge at surgeon's decision when indicated clin- } \\
\text { ically }\end{array}$ & Discharge after fulfilling discharge criteria \\
\hline After discharge & 7 day follow-up in outpatient clinic & $\begin{array}{l}\text { Telephone call on the } 1^{\text {st }} \text { and } 3^{\text {rd }} \text { day after dis- } \\
\text { charge } \\
7 \text { day follow-up in outpatient clinic }\end{array}$ \\
\hline
\end{tabular}

\section{Discussion}

The differences in national health care systems, reimbursement policies and human costs across the countries encouraged us to perform an analysis of economic outcomes of ERP implementation based on a publicly financed academic institution in Poland. In this study we found that laparoscopic surgery combined with ERP is a cost-effective treatment comparing to laparoscopic or open surgery with traditional perioperative care. Additionally it reduces length of stay and postoperative complications. 
Table III. Cost analysis in subsequent groups

\begin{tabular}{|lcccc|}
\hline Parameter & $\begin{array}{c}\text { Group 1 } \\
\text { (Laparoscopic }+ \\
\text { ERP) }\end{array}$ & $\begin{array}{c}\text { Group 2 } \\
\text { (Laparoscopic }+ \\
\text { traditional) }\end{array}$ & $\begin{array}{c}\text { Group 3 } \\
\text { (Open }+ \\
\text { traditional) }\end{array}$ & $P$-value \\
\hline Operative costs, mean \pm SD [EUR] & $1272.1 \pm 345.9$ & $1318.1 \pm 329.2$ & $941.3 \pm 245.2$ & $<0.0001$ \\
\hline Costs of bed stay, mean \pm SD [EUR] & $491.4 \pm 177.0$ & $874.8 \pm 235.9$ & $1324.6 \pm 570.5$ & $<0.0001$ \\
\hline Costs of drugs, mean \pm SD [EUR] & $17.0 \pm 4.6$ & $42.4 \pm 8.6$ & $53.2 \pm 20.7$ & $<0.0001$ \\
\hline Other costs, mean \pm SD [EUR] & $45.5 \pm 60.7$ & $120.0 \pm 31.8$ & $140.4 \pm 267.4$ & 0.0005 \\
\hline Total cost per patient, mean \pm SD [EUR] & $1826.0 \pm 397.7$ & $2355.3 \pm 420.1$ & $2459.5 \pm 575.7$ & $<0.0001$ \\
\hline
\end{tabular}

Table IV. Secondary outcomes

\begin{tabular}{|c|c|c|c|c|}
\hline Parameter & $\begin{array}{c}\text { Group } 1 \\
\text { (Laparoscopic + } \\
\text { ERP) }\end{array}$ & $\begin{array}{c}\text { Group } 2 \\
\text { (Laparoscopic + } \\
\text { traditional) }\end{array}$ & $\begin{array}{c}\text { Group } 3 \\
\text { (Open }+ \\
\text { traditional) }\end{array}$ & $P$-value \\
\hline Number of patients, $n(\%)$ & $33(33.3)$ & $33(33.3)$ & $33(33.3)$ & - \\
\hline Length of stay, median (IQR) [days] & $3(2-4)$ & $6(5-7)$ & $9(7-10)$ & $<0.0001$ \\
\hline Complication rate, $n$ (\%) & $5(15.2)$ & $6(18.2)$ & $13(39.4)$ & 0.0435 \\
\hline Clavien-Dindo 1, n (\%) & $3(9.1)$ & $4(12.1)$ & $6(18.2)$ & \\
\hline Clavien-Dindo 2, n (\%) & $1(3.0)$ & $1(3.0)$ & $4(12.1)$ & \\
\hline Clavien-Dindo 3, n (\%) & - & $1(3.0)$ & $1(3.0)$ & \\
\hline Clavien-Dindo 4, n (\%) & - & - & $2(6.1)$ & \\
\hline Clavien-Dindo 5, n (\%) & $1(3.0)$ & - & - & \\
\hline Intensive care unit stay, $n$ (\%) & $1(3.0)$ & - & $2(6.1)$ & 0.3564 \\
\hline Readmission, $n(\%)$ & $2(6.1)$ & $1(3.0)$ & - & 0.3564 \\
\hline
\end{tabular}

There is currently strong evidence for better short-term outcomes from minimally invasive surgery compared to open resections [1, 22, 23]. However, due to the false impression of higher costs of treatment, it is rarely performed in middle- and low-income countries with limited expenditure on health care [5]. Our paper is in line with previous results stating that the laparoscopic procedure alone is undoubtedly more expensive until LOS, costs of complications and recovery are factored in [24-26]. It is directly related to a longer operative time and increased number of disposable equipment. Therefore, we agree that in our environment it may also be associated with increased expenditure. According to our results, when including other treatment costs (LOS, drugs, complications) in the calculations, minimally invasive surgery turns out to be a cost-effective alternative. Although this has been previously confirmed in studies conducted in high-income countries, data on this topic in a different economic setting are sparse [27-29]. Thus, in the analysis we also included an intermediate group - patients operated on minimally invasively but managed traditionally. Interestingly, we noted that there were no significant differences in direct costs of treatment between laparoscopic and open groups in a traditional care protocol.

In the large multicentre randomized LAFA trial comparing laparoscopic and open techniques within and outside ERP, the authors did not find significant differences in in-hospital costs among the treatment groups [30]. Probably the most important result of our analysis is that a hospital may financially benefit from laparoscopic colorectal procedures only if they are combined with ERP. In our setting, the reduction of costs of hospital stay and drugs in the enhanced recovery after surgery environment overweighed operating room costs both in open and laparoscopic 
groups. The mean difference in overall costs between traditional laparoscopic and ERP groups was EUR 529 $(22.5 \%)$. It is smaller than presented in the recent reviews by Lee et al. and Lemanu et al. [16, 19]. It seems that this discrepancy reflects the total expenditure on the overall costs of treatment of a single patient, which in our case, due to socioeconomic conditions, was significantly lower. This proportion can be additionally enhanced if we take into consideration improved patient bed availability, shorter waiting lists for surgery, fewer cancelations due to the lack of ward capacity and, last but not least, higher total reimbursement due to a higher number of patients treated. The Polish Ministry of Health has recently implemented a new programme for all surgical cancer patients to improve clinical outcomes. It aims to shorten the time from diagnosis to treatment by providing surgeons with better and wider access to diagnostic tools. Moreover, increased financial resources on surgical oncology were allocated. Therefore shortened length of stay and a reduced complication rate increase the capacity of every surgical ward, thus indirectly enabling higher income. In Poland, health care is mostly public funded. Each year the National Health Fund signs individual contracts with Polish hospitals setting down the number and types of individual surgical procedures to be refunded by the state during the next year. The reimbursement for the surgical treatment of a patient depends on the type of surgery (ICD-9) and diagnostic code (ICD-10). The refund is equal regardless of the surgical approach (open/laparoscopic) or postoperative course (prolonged hospital stay, complications). Moreover, any readmission within 14 days after discharge is not refunded and therefore generates debt. For instance, the expenditure on a single colorectal resection is much lower than in other developed countries [16]. This is probably the most important factor which slows down wider implementation of laparoscopy in Poland (mistakenly considered as more expensive). Therefore ERP leading to real cost savings allows us to perform laparoscopic surgery practically in all patients. Further reduction of LOS maximizes hospital bed capacity, thus increasing the number of cases treated annually.

The primary outcome of this study was cost-analysis, but similarly to our previous analyses we also demonstrated that laparoscopy and ERP significantly reduce complications and length of stay [10, 3134]. Previous large trials and meta-analyses clearly showed similar results in terms of both laparoscopy and ERP $[6,9,35]$. Moreover, they did not demonstrate any differences in readmission rates. We can therefore assume that further savings can be made as a result of reduced complications and improved postoperative recovery with no risk of additional costs of readmission.

Another important issue which should be mentioned is neglecting costs of staff training and the ERP implementation process. We have decided to deliberately ignore implementation costs since we believe that once protocols are implemented the training will become "training while working" with regular postgraduate education or refreshment courses. Those costs are the same no matter whether training includes traditional or modern multimodal perioperative care pathways. Obviously implementation of a new protocol may require a costly visit to a centre of excellence. Currently, there are already national symposia in Poland which teach necessary skills of how to implement ERP.

Our study has certain limitations typical for a single-centre non-randomized analysis. However, in our opinion conducting a randomized controlled trial in a centre which implemented ERP 3 years ago for all types of procedures (compliance with ERP in colorectal surgery > 80\%) would not be possible. We cannot imagine how to convince our staff to take a step back and start using the traditional perioperative protocol. It would certainly result in low compliance with the traditional protocol and might create potential bias. Additionally, the costs of certain equipment and drugs as well as bed stay at our institution may be different from other hospitals in our country. Therefore it cannot be directly transferred to all hospitals but may very well serve as a model of a Polish hospital financed by the national health care system. The inclusion of a retrospective group of patients introduces the possibility of some differences in perioperative care, which were not assessed. Finally, we calculated only direct costs (and readmissions within 30 days after discharge), and did not include costs of postoperative care in primary health care after that period.

\section{Conclusions}

The implementation of ERP and laparoscopic colorectal surgery is associated with decreased risk of postoperative complications. Although clinical 
outcomes are the most important measurements in modern surgery, cost analysis remains a significant argument in the discussion on new methods of treatment. Based on our analysis, modern perioperative care combined with minimally invasive surgery can be a cost-effective alternative to open surgery with traditional perioperative care.

\section{Acknowledgments}

Stanisław Kłęk has received honoraria as a lecturer from Baxter, B Braun, Fresenius Kabi, Nestle, and Nutricia. The rest of the authors have no competing interests to declare.

The publication of this paper was supported by the Faculty of Medicine, Jagiellonian University Medical College, Leading National Research Centre (KNOW) 2012-2017.

\section{Conflict of interest}

The authors declare no conflict of interest.

\section{References}

1. Bonjer HJ, Hop WCJ, Nelson H, et al. Laparoscopically assisted vs open colectomy for colon cancer: a meta-analysis. Arch Surg 2007; 142: 298-303.

2. van der Pas MH, Haglind E, Cuesta MA, et al. Laparoscopic versus open surgery for rectal cancer (COLOR II): short-term outcomes of a randomised, phase 3 trial. Lancet Oncol 2013; 14 210-8.

3. Leake PA, Pitzul K, Roberts PO, Plummer JM. Comparative analysis of open and laparoscopic colectomy for malignancy in a developing country. World J Gastrointest Surg 2013; 5: 294-9.

4. Jayne DG, Thorpe HC, Copeland J, et al. Five-year follow-up of the Medical Research Council CLASICC trial of laparoscopically assisted versus open surgery for colorectal cancer. Br J Surg 2010; 97: 1638-45.

5. Baigrie RJ, Stupart D. Introduction of laparoscopic colorectal cancer surgery in developing nations. Br J Surg J 2010; 97: 625-7.

6. Greco M, Capretti G, Beretta L, et al. Enhanced recovery program in colorectal surgery: a meta-analysis of randomized controlled trials. World J Surg 2013; 38: 1531-41.

7. LV L, Shao YF, Zhou YB. The enhanced recovery after surgery (ERAS) pathway for patients undergoing colorectal surgery: an update of meta-analysis of randomized controlled trials. Int J Colorectal Dis 2012; 27: 1549-54.

8. Adamina M, Kehlet $\mathrm{H}$, Tomlinson GA, et al. Enhanced recovery pathways optimize health outcomes and resource utilization: a meta-analysis of randomized controlled trials in colorectal surgery. Surgery 2011; 149: 830-40.

9. Zhuang CL, Ye XZ, Zhang XD, et al. Enhanced recovery after surgery programs versus traditional care for colorectal surgery: a meta-analysis of randomized controlled trials. Dis Colon Rectum 2013; 56: 667-78.

10. Kisialeuski M, Pędziwiatr M, Matłok M, et al. Enhanced recovery after colorectal surgery in elderly patients. Videosurgery Miniinv 2015; 10: 30-6.

11. Lassen K, Hannemann P, Ljungqvist O, et al. Patterns in current perioperative practice: survey of colorectal surgeons in five northern European countries. BMJ 2005; 330: 1420-1.

12. Polle SW, Wind J, Fuhring JW, et al. Implementation of a fasttrack perioperative care program: what are the difficulties? Dig Surg 2007; 24: 441-9.

13. Maessen J, Dejong CHC, Hausel J, et al. A protocol is not enough to implement an enhanced recovery programme for colorectal resection. Br J Surg 2007; 94: 224-31.

14. Hughes M, Coolsen MME, Aahlin EK, et al. Attitudes of patients and care providers to enhanced recovery after surgery programs after major abdominal surgery. J Surg Res 2015; 193: 102-10.

15. Kehlet H, Büchler MW, Beart RW, et al. Care after colonic operation: is it evidence-based? Results from a multinational survey in Europe and the United States. J Am Coll Surg 2006; 202: 45-54.

16. Lee L, Li C, Landry T, et al. A systematic review of economic evaluations of enhanced recovery pathways for colorectal surgery. Ann Surg 2014; 259: 670-6.

17. Lee L, Mata J, Ghitulescu GA, et al. Cost-effectiveness of enhanced recovery versus conventional perioperative management for colorectal surgery. Ann Surg 2015; 262: 1026-33.

18. Roulin D, Donadini A, Gander S, et al. Cost-effectiveness of the implementation of an enhanced recovery protocol for colorectal surgery. Br J Surg 2013; 100: 1108-14.

19. Lemanu DP, Singh PP, Stowers MDJ, Hill AG. A systematic review to assess cost effectiveness of enhanced recovery after surgery programmes in colorectal surgery. Colorectal Dis 2014; 16: 338-46.

20. Sosada K, Wiewiora M, Piecuch J, Zurawiński W. Fast track in large intestine surgery - review of randomized clinical trials. Videosurgery Miniinv 2013; 8: 1-7.

21. Clavien PA, Barkun J, de Oliveira ML, et al. The Clavien-Dindo classification of surgical complications: five-year experience. Ann Surg 2009; 250: 187-96.

22. Abraham NS, Young JM, Solomon MJ. Meta-analysis of shortterm outcomes after laparoscopic resection for colorectal cancer. Br J Surg 2004; 91: 1111-24.

23. Arezzo A, Passera R, Scozzari G, et al. Laparoscopy for rectal cancer reduces short-term mortality and morbidity: results of a systematic review and meta-analysis. Surg Endosc 2013; 27 : 1485-502.

24. Winter DC. The cost of laparoscopic surgery is the price of progress. Br J Surg 2009; 96: 327-8.

25. Noblett SE, Horgan AF. A prospective case-matched comparison of clinical and financial outcomes of open versus laparoscopic colorectal resection. Surg Endosc 2006; 21: 404-8.

26. Dowson HM, Huang A, Soon Y, et al. Systematic review of the costs of laparoscopic colorectal surgery. Dis Colon Rectum 2007; 50: 908-19. 
27. Ridgway PF, Boyle E, Keane FB, Neary P. Laparoscopic colectomy is cheaper than conventional open resection. Colorectal Dis 2007; 9: 819-24.

28. Shabbir A, Roslani AC, Wong KS, et al. Is laparoscopic colectomy as cost beneficial as open colectomy? ANZ I Surg 2009; 79: 265-70.

29. Hardy KM, Kwong J, Pitzul KB, et al. A cost comparison of laparoscopic and open colon surgery in a publicly funded academic institution. Surg Endosc 2013; 28: 1213-22.

30. Vlug MS, Wind J, Hollmann MW, et al. Laparoscopy in combination with fast track multimodal management is the best perioperative strategy in patients undergoing colonic surgery: a randomized clinical trial (LAFA-study). Ann Surg 2011; 254: 868-75.

31. Pędziwiatr M, Kisialeuski M, Wierdak M, et al. Early implementation of Enhanced Recovery After Surgery (ERAS( $\left({ }^{\circledR}\right)$ ) protocol - compliance improves outcomes: a prospective cohort study. Int J Surg 2015; 21: 75-81.

32. Pędziwiatr M, Matłok M, Kisialeuski M, et al. Enhanced recovery (ERAS) protocol in patients undergoing laparoscopic total gastrectomy. Videosurgery Miniinv 2014; 9: 252-7.

33. Matłok M, Pędziwiatr M, Major P, et al. One hundred seventy-nine consecutive bariatric operations after introduction of protocol inspired by the principles of enhanced recovery after surgery (ERAS $\left.{ }^{8}\right)$ in bariatric surgery. Med Sci Monit 2015; 21:791-7.

34. Pędziwiatr M, Matłok M, Kisialeuski M, et al. Short hospital stays after laparoscopic gastric surgery under an Enhanced Recovery After Surgery (ERAS) pathway: experience at a single center. Eur Surg 2014; 46: 128-32.

35. King PM, Blazeby JM, Ewings P, et al. The influence of an Enhanced Recovery Programme on clinical outcomes, costs and quality of life after surgery for colorectal cancer. Colorectal Dis 2006; 8: 506-13.

Received: 25.01.2016, accepted: 29.02.2016. 